\title{
Placental abruption in immigrant women: a Norwegian population-based study
}

\author{
Karolina S. Mæland ${ }^{1}$, Nils-Halvdan Morken ${ }^{2}$, Erica Schytt $^{3}$, Vigdis Aasheim ${ }^{1}$, and Roy \\ Nilen ${ }^{1}$ \\ ${ }^{1}$ Western Norway University of Applied Sciences \\ ${ }^{2}$ University of Bergen \\ ${ }^{3}$ Center for Clinical Research Dalarna
}

November 2, 2020

\begin{abstract}
Objective To estimate the incidence of placental abruption in immigrant women compared with non-immigrants by maternal country and region of birth, reason for immigration and length of residence. Design Nationwide population-based study. Setting Data from the Medical Birth Registry of Norway and Statistics Norway (1990-2016). Sample The study sample included 1,558,174 pregnancies, in which immigrant women accounted for 245,887 pregnancies and 1,312,287 pregnancies were to nonimmigrants. Methods Crude and adjusted odds ratios with $95 \%$ confidence intervals (CI) for placental abruption in immigrant women compared to non-immigrants were estimated by logistic regression with robust standard error estimations (accounting for within-mother clustering). Adjustment variables included year of birth, maternal age, parity, multiple pregnancies, chronic hypertension and level of education. Main outcome measures Placental abruption Results The incidence of placental abruption decreased during the study period for both immigrants (from $0.68 \%$ to $0.44 \%$ ) and non-immigrants (from $0.80 \%$ to $0.34 \%$ ). Immigrant women from the sub-Saharan African region had an adjusted odds ratio of 1.35 (95\% CI: 1.15-1.58) compared to non-immigrants for placental abruption, whereas immigrant women from Ethiopia had an adjusted odds ratio of 2.39 (95\% CI 1.67-3.41). We found a small variation in placental abruption incidence by other countries or regions of birth, length of residence and reason for immigration. Conclusion Immigrant women from sub-Saharan Africa, especially Ethiopia, have increased odds for placental abruption when giving birth in Norway. Reason for immigration and length of residence had little impact on the incidence of placental abruption.
\end{abstract}

Placental abruption in immigrant women: a Norwegian population-based study

Karolina S. Mæland, RN, RM, PhD-candidate ${ }^{1}$

Nils-Halvdan Morken, $\mathrm{MD}, \mathrm{PhD}^{2,3}$

Erica Schytt, RN, RM, $\mathrm{PhD}^{4,5}$

Vigdis Aasheim, RN, RM, $\mathrm{PhD}^{1}$

Roy Miodini Nilsen, MSc, $\mathrm{PhD}^{1}$

${ }^{1}$ Department of Health and Caring Sciences, Western Norway University of Applied Sciences, Norway

${ }^{2}$ Department of Clinical Science, University of Bergen, Bergen, Norway

${ }^{3}$ Centre for Fertility and Health, Norwegian Institute of Public Health, Oslo, Norway

${ }^{4}$ Centre for Clinical Research Dalarna, Uppsala University, Sweden 
${ }^{5}$ Division of Reproductive Health, Department of Women's and Children's Health, Karolinska Institute, Sweden

Corresponding author: Karolina S. Mæland, Department of health and caring sciences, Faculty of Health and Social Sciences, Western Norway University of Applied Sciences, Inndalsveien 28, 5063 Bergen, Norway. Telephone number: (+47) 555876 65, e-mail:karolina.meland@hvl.no

Running title: Placental abruption in immigrant women

\section{Abstract}

\section{Objective}

To estimate the incidence of placental abruption in immigrant women compared with non-immigrants by maternal country and region of birth, reason for immigration and length of residence.

\section{Design}

Nationwide population-based study.

\section{Setting}

Data from the Medical Birth Registry of Norway and Statistics Norway (1990-2016).

\section{Sample}

The study sample included 1,558,174 pregnancies, in which immigrant women accounted for 245,887 pregnancies and 1,312,287 pregnancies were to non-immigrants.

\section{Methods}

Crude and adjusted odds ratios with $95 \%$ confidence intervals (CI) for placental abruption in immigrant women compared to non-immigrants were estimated by logistic regression with robust standard error estimations (accounting for within-mother clustering). Adjustment variables included year of birth, maternal age, parity, multiple pregnancies, chronic hypertension and level of education.

\section{Main outcome measures}

Placental abruption

\section{Results}

The incidence of placental abruption decreased during the study period for both immigrants (from $0.68 \%$ to $0.44 \%$ ) and non-immigrants (from $0.80 \%$ to $0.34 \%$ ). Immigrant women from the sub-Saharan African region had an adjusted odds ratio of 1.35 (95\% CI: 1.15-1.58) compared to non-immigrants for placental abruption, whereas immigrant women from Ethiopia had an adjusted odds ratio of 2.39 (95\% CI 1.67-3.41). We found a small variation in placental abruption incidence by other countries or regions of birth, length of residence and reason for immigration.

\section{Conclusion}

Immigrant women from sub-Saharan Africa, especially Ethiopia, have increased odds for placental abruption when giving birth in Norway. Reason for immigration and length of residence had little impact on the incidence of placental abruption.

\section{Funding}

Faculty of Health and Sciences (Western Norway University of Applied Sciences) was the main funder. Additional data costs were funded by the Norwegian SIDS and Stillbirth Society.

\section{Keywords}

Placental abruption, immigration, pregnancy, country of birth, perinatal epidemiology 


\section{Tweetable abstract}

Incidence of placental abruption in immigrant women by maternal country of birth, reason for immigration and length of residence

\section{Introduction}

Placental abruption is a rare but serious complication affecting 3 to 10 per 1000 pregnancies worldwide (1, 2 ). It is a clinical diagnosis defined as partial or complete detachment of the placenta before delivery (2). The complication is associated with maternal and perinatal morbidity and mortality and accounts for around $10 \%$ of all perinatal deaths in developed countries (2). The most common risk factors include hypertension (3), pre-eclampsia (4), smoking (5) and the extremes of maternal age (1,2). A genetic predisposition also seems to be implicated; women experiencing abruption in one pregnancy have an 11-fold increased risk of having an abruption in a subsequent pregnancy $(5,6)$. Abruption also occurs however, in the absence of these factors. Knowledge about additional contributing factors is important to better explain the variation of this complication in the population.

In Europe, immigrant women represent a significant proportion of all childbearing women (7) and in Norway, $29 \%$ of all births in 2019 were to immigrant women (8). Immigrants comprise a heterogeneous group, with diverse backgrounds and immigration reasons and they differ in relation to the known risk factors for placental abruption, including hypertension and smoking (9). Refugees are considered a vulnerable group for adverse pregnancy outcomes (10), while women immigrating for work or educational reasons may have equivalent or even better outcomes than the receiving population (11). Some immigrants also appear to have better health upon arrival than the host population though this may worsen over time (9).

Few studies have compared the occurrence of placental abruption between immigrant and non-immigrant women. Among those who have, an increased risk has been found for black women compared to white women $(2,12)$, and the risk of abruption for immigrants as a group seems to increase with length of residence in the receiving country (13). However, the analyses in these studies have not been performed according to specific maternal country or region of birth nor by reason for immigration, so potential variations in placental abruption may be masked in grouping all immigrant women together. The aims of this study were to estimate the incidence of placental abruption in immigrant women in Norway compared to non-immigrants by maternal country and region of birth, reason for immigration and length of residence.

\section{Methods}

\section{Data sources}

We used data from the Medical Birth Registry of Norway (MBRN) and Statistics Norway during 1990-2016. In brief, the MBRN comprises mandatory, standardized notification of all live- and stillbirths in Norway from 16 weeks of gestation (12 weeks of gestation from 2001). It contains information on maternal health before and during pregnancy, as well as information on maternal and infant health during labour and birth (14). Statistics Norway collects, processes and disseminates official statistics in Norway (15). The data collection includes sociodemographic and migration related factors about all individuals who are or have been resident in Norway since 1990 (16). Data from the MBRN and Statistics Norway were linked using the national identity number assigned to all residents in Norway.

\section{Study sample}

The total source population from the MBRN between 1990 and 2016 contained data from 1,593,281 pregnancies (Fig. 1). Of these, we analysed 1,558,174 pregnancies, of which $16 \%(n=245,887)$ were to immigrant women (foreign-born women with two foreign-born parents) and $84 \%(n=1,312,287)$ were to non-immigrants (Norwegian-born women with at least one Norwegian-born parent). We excluded pregnancies due to missing data on maternal country of birth (518 pregnancies), pregnancies to foreign-born women with a Norwegianborn parent(s) (25,661 pregnancies) and pregnancies to Norwegian-born women with two foreign-born parents (8,928 pregnancies). 


\section{Placental abruption}

Placental abruption is a clinical diagnosis, identified by uterine tenderness, antepartum haemorrhage and/or foetal distresses $(1,2)$. The diagnosis in this study was based on coding according to the International Statistical Classification of Disease and Related Health Problems, $8^{\text {th }}$ revision $(1990-98)$ and $10^{\text {th }}$ revision (1999 onwards) from the MBRN and included both partial and complete detachment of the placenta before delivery. The diagnosis was recorded by a check box or in open text on the standardized MBRN-notification form.

\section{Migration related factors}

The Global Burden of Diseases (GBD) study represents a major international effort that quantifies levels and trends in health to allow for comparison of the magnitude of different risk factors and health outcomes in the world (17). We analysed data by maternal region of birth using the seven super regions defined by the GBD: (i) Central Europe, Eastern Europe and Central Asia; (ii) High-income; (iii) Latin America and Caribbean; (iv) North Africa and Middle East; (v) South Asia; (vi) Southeast Asia, East Asia and Oceania; (vii) Sub-Saharan Africa.

Separate analyses by maternal country of birth were also performed for all countries with more than 6000 registered pregnancies (14 countries) or more than 15 registered placental abruptions (an additional 11 countries) during the study period. Immigrant women from countries with fewer abruptions or pregnancies were grouped and coded as other countries. Reason for immigration included: education, family reunion/establishment, refugee, work, unspecified/other (8). Women from the Nordic countries (Denmark, Sweden, Finland and Iceland) are permitted to move freely across the Nordic countries and were included as a separate category (Nordic immigrants ). Maternal length of residence was categorized as $<1$ year, 1-4 years, [?] 5 years and was calculated as the difference between the year of birth and the year of official residence permit.

\section{Other variables}

Detailed background information was extracted from the MBRN and included marital status (married/cohabiting, not married/cohabiting), maternal age at birth (years), parity (0, 1, 2, 3, [?]4), multiple pregnancies (yes/no), chronic hypertension (yes/no), and maternal smoking ( $1^{\text {st }}$ trimester: yes, no, not reported; available from 1999 onwards). From Statistics Norway, we extracted data on maternal level of education (no education, primary school, secondary school, university/college). All variables were selected due to their possible association with either the exposure or the outcome and were treated as potential covariates in the regression models.

\section{Statistical analyses}

To investigate possible associations of maternal country and region of birth, reason for immigration and length of residence with placental abruption, we estimated odds ratios (ORs) with $95 \%$ confidence intervals (CIs) using binary logistics regression analysis. Maternal country of birth, maternal region of birth, reason for immigration and length of residence were included in the regression models as categorical variables using non-immigrant women as the reference group.

Adjustments were made for year of birth, maternal age, parity, multiple pregnancies, chronic hypertension and level of education. Year of birth and maternal age at the birth were included as polynomial quadratic terms in the regression. To account for dependency among pregnancies to the same woman, we used robust standard errors that allowed for within-mother clustering (18).

Missing values were imputed with the mi suite of commands in Stata, using the multivariate normal model with five imputations (19). The imputations were performed for each exposure-outcome association and included the same variables as in the analytic regression models. To obtain ORs with $95 \%$ CI across the five imputed datasets, we used Rubin's combination rules, adjusted for the variability between imputation sets. 
To investigate the possible impact of smoking on study results, we performed analyses for the sub-period 1999-2016 for which smoking data were available. Adjustment for smoking had little impact on the reported results (data not shown). Similarly, adjustments for consanguinity between mother and father or Norwegian health region for the birth did not change the results and were therefore not included in the models.

All analyses were performed using Stata IC version 16 (Stata Statistical Software, College Station, TX, USA).

\section{Results}

The characteristics of the study samples are outlined in Table S1. Among the immigrants, women from Central Europe, Eastern Europe and Central Asia, comprised the largest group $(n=56,466)$, while those from Latin America and Caribbean $(n=6,451)$ represented the smallest group. Mean maternal age across groups ranged from 28.5 to 31.2 years.

Immigrant women born in sub-Saharan Africa had higher parity and, lower education levels, but were less likely to be smokers. In contrast, women from high income countries had the highest level of education. Non-immigrant women were more likely to be smokers during pregnancy, compared to all other groups.

The mean length of residence among immigrants ranged from 5.0 to 8.6 years. Close to $50 \%$ of the subSaharan immigrants were registered as refugees, which is by far the highest among all the regions of birth. More than $50 \%$ of the immigrant women born in countries defined ashigh-income were Nordic immigrants .

The overall incidence of placental abruption was $0.47 \%$ for both immigrants and non-immigrants. There was a significant decrease in placental abruption for both groups over the study period. The decrease in immigrants was from $0.68 \%$ to $0.44 \%$ while the decrease in non-immigrants was from $0.80 \%$ in 1990 to $0.34 \%$ in 2016, (Fig. S1).

Immigrant women born in the sub-Saharan African region had the highest incidence of placental abruption $(0.62 \%)$, while the lowest incidence $(0: 39 \%)$ was found in immigrants from Central Europe, Eastern Europe or Central Asia (Fig. 2; Table 1). When compared to non-immigrants, the adjusted OR for placental abruption was 1.35 [95\% CI: 1.15-1.58] for women from sub-Saharan Africa and 1.05 [0.92-1.21] for women from Central Europe, Eastern Europe or Central Asia (Table 1).

The adjusted ORs for placental abruption by maternal country of birth relative to non-immigrant women is presented in Fig. 3. A strong association was found for immigrant women born in Ethiopia (2.39 [1.67-3.41]). A higher OR was also found for Brazilian women (1.58 [0.95-2.63]), but the confidence interval was wide.

Compared with non-immigrants, we found a weak association between length of residence and placental abruption for immigrants with 1-4 years of residence in Norway (1.13 [1.03-1.24]). There was also a slightly higher OR for abruption for refugees (1.15 [0.99-1.33]).

\section{Discussion}

\section{Main findings}

The main finding of this study was that immigrant women from sub-Saharan Africa, especially Ethiopia, had an increased incidence of placental abruption, compared to the non-immigrant group. We found little variation in the occurrence of placental abruption by length of residence or reason for immigration.

\section{Strengths and Limitations}

The strengths of this study are the large sample size and the nationwide population-based design, allowing precise selection and adjustments of covariates in the regression models, detailed analysis by country of birth, as well as investigation of trends over time for placental abruption for both immigrant and nonimmigrant women. However, our results should be interpreted with some caution. We did not adjust for maternal body mass index as this variable was only available from 2008 onwards. Body mass index has been associated with country of birth and is differently distributed among immigrant groups (20). As maternal 
weight in pregnancy might be associated with placental abruption, it is possible that our results are over- or underestimated as the body mass index distribution varies between the countries represented in the study sample. Furthermore, our study focused on foreign-born women with foreign-born parents (i.e. $1^{\text {st }}$ generation immigrant women). The results can therefore not be generalized to Norwegian born women with foreignborn parents or to foreign-born women with Norwegian-born parents. Additionally, as placental abruption is a clinical diagnosis that is lacking unified diagnostic criteria across Norwegian hospitals, misclassification of placental abruption cannot be excluded.

\section{Interpretation}

Immigrant women born in Ethiopia had an increased incidence of placental abruption compared with nonimmigrants. Ethiopia is a large country with several regions and different ethnic communities, and the incidence of abruption is known to vary by region (21). The region an Ethiopian woman comes from is not registered upon arrival in Norway and it is possible that they are more likely to come from regions with a higher background incidence of placental abruption. A higher abruption incidence may also be attributed to nutritional factors. Immigrant women from Ethiopia appears to have a higher prevalence of vitamin D deficiency (22) as well as a lower prevalence of folic acid supplement use than other immigrants (23). Both these factors have previously been linked to placental vascular pathology (24-26).

Immigrant women from sub-Saharan Africa have been reported to receive suboptimal healthcare during pregnancy compared with non-immigrants in Norway (27). They also have a higher risk of several adverse outcomes in pregnancy, including stillbirth (28), hypertension (29), pre-eclampsia (29) and gestational diabetes (30). Chronic hypertension and pre-eclampsia are well-known risk factors for placental abruption, and an increased association also for placental abruption in immigrant women from sub-Saharan Africa might therefore not be unexpected. Somewhat surprisingly though, the OR was only moderately increased for this group. Our finding is in contrast to previous studies from the United States suggesting that black women have a substantially higher OR for placental abruption compared to white women $(12,31)$. The discrepancy between findings may however be due to methodological differences where aggregation of women into even larger categories (black and white) may result in different outcomes. Furthermore, our study focused on $1^{\text {st }}$ generation immigrant women and not on race, which further complicates comparison of study results. In addition, the different composition of the immigrant population in Norway compared to the United States and dissimilarity in various risk factors associated with abruption may further explain the difference in ORs between studies.

We found a slightly higher incidence of placental abruption in refugees. Refugees comprise a vulnerable group, often with poor health and low socioeconomic status (11) and are known to have an increased risk of preterm pre-eclampsia (9) and preterm birth (32). When addressing the different needs of immigrants we must recognize the complexity of immigration (2). For some immigrants, strong health made migration possible in the first place, yet others have been forced to flee from war or natural disasters and may be of poorer health and with history of trauma. The process of refuge may be stressful, and refugees are exposed to various health risks and are generally in more vulnerable situations (10). Maternal stress during pregnancy is a potential risk factor for abruption (33) and the challenges faced by refugee women likely add significant stress in the whole process of immigration. In addition, refugees may face structural barriers with difficulties accessing information and advice during pregnancy in the receiving country, reducing the understanding of signs, symptoms and responses to pathology (10).

Several risk factors for placental abruption seems to increase with length of residence in the receiving country (34). For instance, a previous Norwegian study found an increased incidence of pre-eclampsia with increasing length of residence in immigrant women, particularly in women arriving for family reunion or establishment (9). Moreover, a Canadian study found that the risk of pre-eclampsia/eclampsia, placental abruption and placental infarction was significantly reduced in immigrant women with less than three months in Canada compared to those with more than 5 years of residence (13), possibly due to an adoption of a less healthy lifestyle after migration (13). These findings were not confirmed in our study where we found only a weak association for abruption in immigrants with 1-4 years of residence in Norway. These difference in findings 
could be due to methodological differences as the Canadian study presented only crude estimates with no adjustment for covariates.

There has been a temporal decline in placental abruption for both non-immigrants and immigrants over the last decades. In our study the incidence of abruption was $0.47 \%$, which is lower than in the USA and Canada (1) but consistent with other Nordic countries $(1,35)$. In the United States the abruption incidence has plateaued; (1) however, the significant decline in abruptions in our study is also seen across many European countries over the last decade $(1,35)$. The reason for this decline may be attributable to a change in specific risk factors for abruption, like smoking. Compared to the host population, immigrants are less likely to smoke and in Norway smoking habits have declined significantly in recent times in both non-immigrants and immigrants (36). In Sweden and the United States a change in smoking habits was associated with a decline in abruption risk (1), and this may also partly explain the decrease in abruptions in Norway.

\section{Conclusions}

In this nationwide population-based study, immigrant women from sub-Saharan Africa, and especially Ethiopia, had an increased incidence of placental abruption after immigration to Norway. We did not find much variation in placental abruption incidence by reason for immigration or length of residence. Our results are important for maternity caregivers, who support women to achieve a healthy lifestyle and optimization of nutrition during pregnancy, as well as provide targeted information on early signs of abruption for immigrant women from sub-Saharan Africa, especially Ethiopia during pregnancy.

\section{Abbreviations}

aOR: Adjusted Odds Ratio; CI: Confidence Interval; MBRN: Medical Birth Register Norway; OR: Odds Ratio

\section{Acknowledgements}

We thank the Medical Birth Registry of Norway (MBRN) and Statistics Norway for providing data for this study.

\section{Disclosure of Interests}

None declared.

\section{Contribution to Authorship}

RMN, VA and ES contributed to the conceptualization, design and planning of this study; KSM analysed the data and wrote the original draft of the manuscript; RMN made substantial contribution to interpretation of data analyses and revision of the manuscript; KSM and RMN are responsible for the reviewing and editing of the manuscript; RMN and N-HM reviewed the methodology and analyses, and contributed in the reviewing to the manuscript; VA, ES and RS contributed to the revising of the manuscript. All authors read and approved the final manuscript.

\section{Details of Ethics Approval}

This study was approved by the South-East Regional Committees for Medical and Health Research Ethics in Norway 01.08.2014 (reference number: 2014/1278). Data were used under licence for this study.

\section{Funding}

Faculty of Health and Sciences (Western Norway University of Applied Sciences) was the main funder. Additional data costs were funded by the Norwegian SIDS and Stillbirth Society.

\section{Availability of data and materials}

Data are available from the author upon request and with permission of the Medical Birth Registry of Norway and Statistics Norway. 


\section{References}

1. Ananth CV, Keyes KM, Hamilton A, Gissler M, Wu C, Liu S, et al. An international contrast of rates of placental abruption: an age-period-cohort analysis. PLoS One. 2015;10(5):e0125246.

2. Tikkanen M. Placental abruption: epidemiology, risk factors and consequences. Acta Obstet Gynecol Scand. 2011;90(2):140-9.

3. Ananth CV, Peltier MR, Kinzler WL, Smulian JC, Vintzileos AM. Chronic hypertension and risk of placental abruption: is the association modified by ischemic placental disease? Am J Obstet Gynecol. 2007;197(3):273.e1-7.

4. Tikkanen M. Etiology, clinical manifestations, and prediction of placental abruption. Acta Obstet Gynecol Scand. 2010;89(6):732-40.

5. Ananth CV, Cnattingius S. Influence of maternal smoking on placental abruption in successive pregnancies: a population-based prospective cohort study in Sweden. Am J Epidemiol. 2007;166(3):289-95.

6. Rasmussen S, Irgens LM. Occurrence of placental abruption in relatives. Bjog. 2009;116(5):693-9.

7. Bevelander P, H. Bilde R, Dahlstedt I, Eskelund M, Moller Hansen L, Macura M, et al. Scandinavia's Population Groups Originating from Developing Countries: Change and Integration. Copenhagen: Nordic Council of Ministers; 2013 2013. 243 p.

8. Statistics Norway. Immigrants and Norwegian-born to immigrant parents 2019 [Available from:https://www.ssb.no/en/befolkning/statistikker/innvbef/aar.

9. Nilsen RM, Vik ES, Rasmussen SA, Small R, Moster D, Schytt E, et al. Preeclampsia by maternal reasons for immigration: a population-based study. BMC pregnancy and childbirth. 2018;18(1):423.

10. Goodman RD, Vesely CK, Letiecq B, Cleaveland CL. Trauma and Resilience Among Refugee and Undocumented Immigrant Women. Journal of Counseling \& Development. 2017;95(3):309-21.

11. Gagnon AJ, Zimbeck M, Zeitlin J, Alexander S, Blondel B, Buitendijk S, et al. Migration to western industrialised countries and perinatal health: a systematic review. Soc Sci Med. 2009;69(6):934-46.

12. Shen TT, DeFranco EA, Stamilio DM, Chang JJ, Muglia LJ. A population-based study of race-specific risk for placental abruption. BMC pregnancy and childbirth. 2008;8:43-.

13. Ray JG, Vermeulen MJ, Schull MJ, Singh G, Shah R, Redelmeier DA. Results of the Recent Immigrant Pregnancy and Perinatal Long-term Evaluation Study (RIPPLES). CMAJ : Canadian Medical Association journal $=$ journal de l'Association medicale canadienne. 2007;176(10):1419-26.

14. Irgens LM. The Medical Birth Registry of Norway. Epidemiological research and surveillance throughout 30 years. Acta Obstet Gynecol Scand. 2000;79(6):435-9.

15. Statistics Norway. About Statistics Norway 2020 [Available from:https://www.ssb.no/en/omssb/om-oss.

16. Dzamarija M. Statistics on reasons for immigration 1990-2011, what do we know and how can we best use this information. Oslo-Kongsvinger: Statistics Norway. 2013.

17. Global Burden of Disease (GBD). What Countries Are in Each Region? : Institute for Health Metrics and Evaluation; [Available from:http://www.healthdata.org/gbd/faq.

18. Ananth CV, Platt RW, Savitz DA. Regression models for clustered binary responses: implications of ignoring the intracluster correlation in an analysis of perinatal mortality in twin gestations. Ann Epidemiol. 2005;15(4):293-301.

19. StataCorp. Stata Multiple-Imputation. 16 ed. 
20. Torkildsen SE, Svendsen H, Raisanen S, Sole KB, Laine K. Country of birth and county of residence and association with overweight and obesity - a population-based study of 219555 pregnancies in Norway. Journal of Public Health. 2019;41(4):e290-e9.

21. Mersha AG, Abegaz TM, Seid MA. Maternal and perinatal outcomes of hypertensive disorders of pregnancy in Ethiopia: systematic review and meta-analysis. BMC pregnancy and childbirth. 2019;19(1):458.

22. Fogelman Y, Rakover Y, Luboshitzky R. High prevalence of vitamin D deficiency among Ethiopian women immigrants to Israel: exacerbation during pregnancy and lactation. Isr J Med Sci. 1995;31(4):221-4.

23. Nilsen RM, Daltveit AK, Iversen MM, Sandberg MG, Schytt E, Small R, et al. Preconception Folic Acid Supplement Use in Immigrant Women (1999-2016). Nutrients. 2019;11(10).

24. Haugen M, Brantsaeter AL, Trogstad L, Alexander J, Roth C, Magnus P, et al. Vitamin D supplementation and reduced risk of preeclampsia in nulliparous women. Epidemiology. 2009;20(5):720-6.

25. Nilsen RM, Vollset SE, Rasmussen SA, Ueland PM, Daltveit AK. Folic acid and multivitamin supplement use and risk of placental abruption: a population-based registry study. Am J Epidemiol. 2008;167(7):867-74.

26. Gernand AD, Bodnar LM, Klebanoff MA, Parks WT, Simhan HN. Maternal serum 25-hydroxyvitamin $\mathrm{D}$ and placental vascular pathology in a multicenter US cohort. The American journal of clinical nutrition. 2013;98(2):383-8.

27. Saastad E, Vangen S, Froen JF. Suboptimal care in stillbirths - a retrospective audit study. Acta Obstet Gynecol Scand. 2007;86(4):444-50.

28. Vik ES, Aasheim V, Schytt E, Small R, Moster D, Nilsen RM. Stillbirth in relation to maternal country of birth and other migration related factors: a population-based study in Norway. BMC pregnancy and childbirth. 2019;19(1):5-.

29. Urquia M, Glazier R, Gagnon A, Mortensen L, Nybo Andersen A-M, Janevic T, et al. Disparities in pre-eclampsia and eclampsia among immigrant women giving birth in six industrialised countries. Bjog. 2014;121(12):1492-500.

30. Urquia M, Glazier RH, Berger H, Ying I, De Souza L, Ray JG. Gestational Diabetes Among Immigrant Women. Epidemiology. 2011;22(6):879-80.

31. Ananth CV, Oyelese Y, Yeo L, Pradhan A, Vintzileos AM. Placental abruption in the United States, 1979 through 2001: temporal trends and potential determinants. Am J Obstet Gynecol. 2005;192(1):191-8.

32. Liu C, Urquia M, Cnattingius S, Hjern A. Migration and preterm birth in war refugees: a Swedish cohort study. Eur J Epidemiol. 2014;29(2):141-3.

33. de Paz NC, Sanchez SE, Huaman LE, Chang GD, Pacora PN, Garcia PJ, et al. Risk of placental abruption in relation to maternal depressive, anxiety and stress symptoms. J Affect Disord. 2011;130(12):280-4.

34. Naimy Z, Grytten J, Monkerud L, Eskild A. The prevalence of pre-eclampsia in migrant relative to native Norwegian women: a population-based study. Bjog. 2015;122(6):859-65.

35. TIKKANEN M, RIIHIMAKI O, GISSLER M, LUUKKAALA T, METSARANTA M, ANDERSSON $\mathrm{S}$, et al. Decreasing incidence of placental abruption in Finland during 1980-2005. Acta Obstetricia et Gynecologica Scandinavica. 2012;91(9):1046-52.

36. Grotvedt L, Kvalvik LG, Groholt E-K, Akerkar R, Egeland GM. Development of Social and Demographic Differences in Maternal Smoking Between 1999 and 2014 in Norway. Nicotine \& Tobacco Research. 2017;19(5):539-46. 


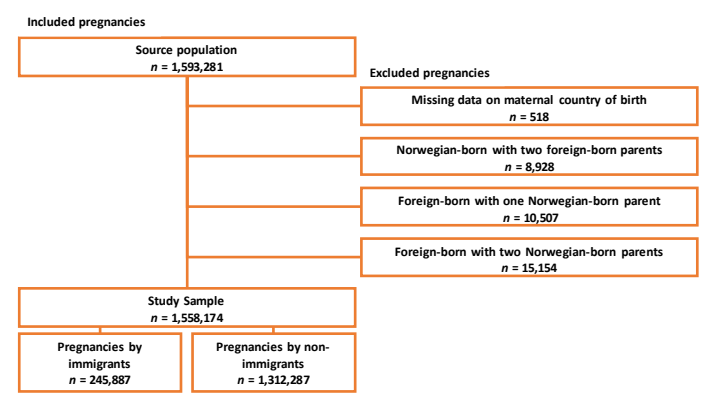

\section{Hosted file}

Table 1 Odds ratios by GBD.pdf available at https://authorea.com/users/372233/articles/ 490345-placental-abruption-in-immigrant-women-a-norwegian-population-based-study

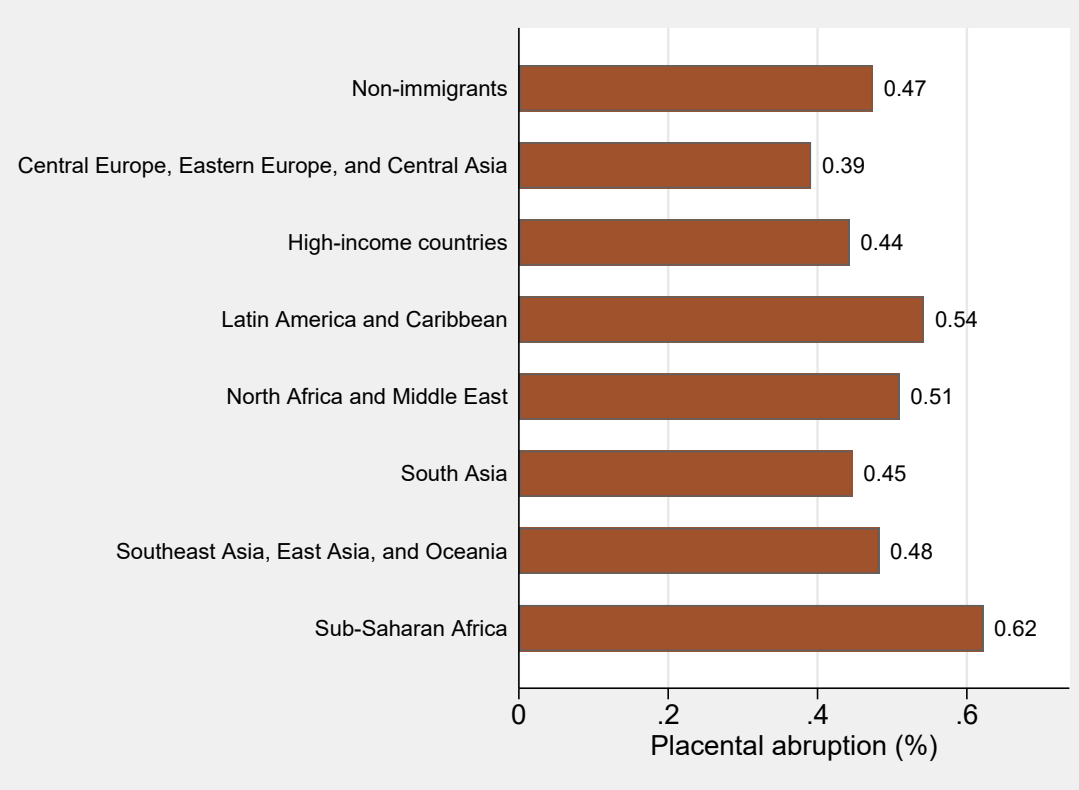




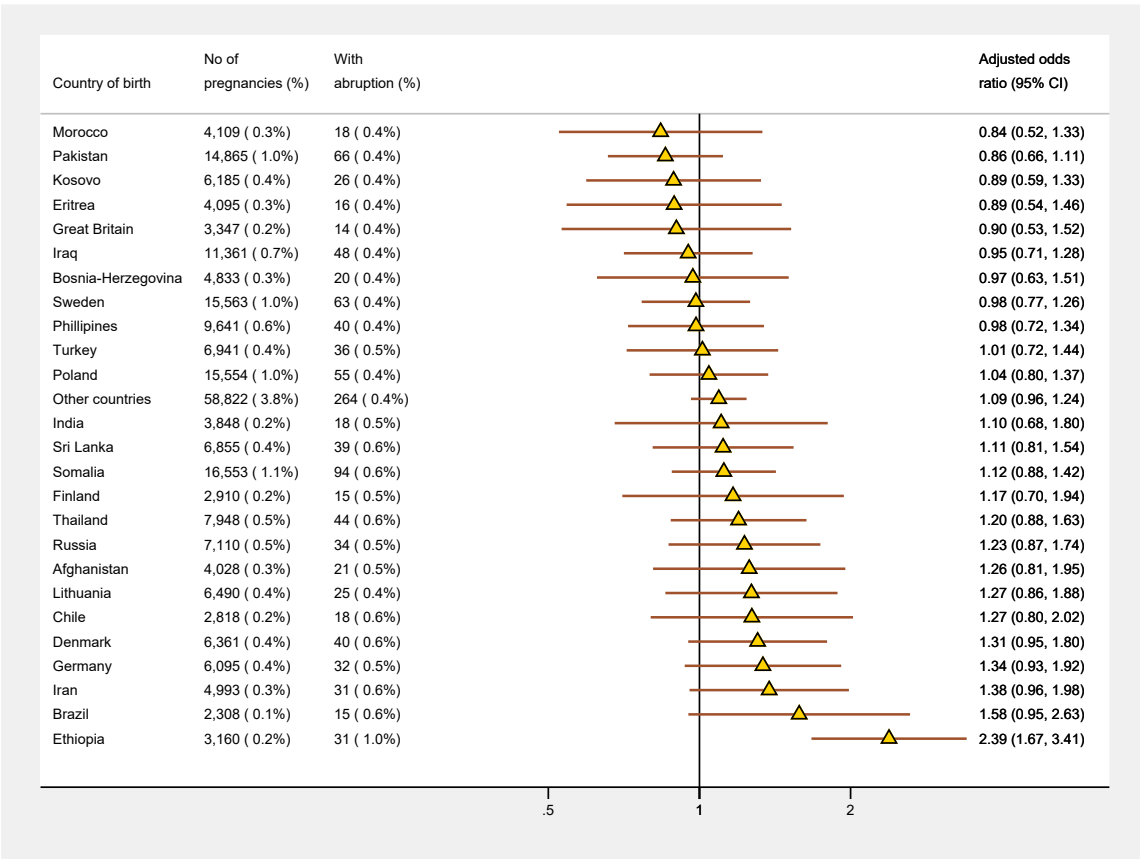

